\title{
Analysis of the Mechanical Properties Change of PA6/MMT Nanocomposite System after Ageing DULEBOVÁ L'udmila ${ }^{1, a^{*}}$, GREŠKOVIČ František ${ }^{1, b}$, SIKORA Janusz W. ${ }^{2, c}$ and KRASINSKYI Volodymyr ${ }^{3, d}$ \\ ${ }^{1}$ Technical University of Košice, Department of Automobile Production, Mäsiarska 74, 04001 Košice, Slovakia \\ ${ }^{2}$ Lublin University of Technology, Department of Polymer Processing, Lublin 36 Nadbystrzycka St., 20-618 Lublin, Poland \\ ${ }^{3}$ Lviv Polytechnic National University, Department of Chemical Technology of Plastics, 12, Bandera Str., Lviv, 79013, Ukraine \\ a ludmila.dulebova@tuke.sk, ${ }^{b}$ frantisek.greskovic@tuke.sk, ${ }^{c}$ j.sikora@pollub.pl, \\ dvkrasinsky82@gmail.com
}

Keywords: polymer nanocomposites, nanoclay fillers, mechanical properties, plastics ageing, polyamide

\begin{abstract}
The paper deals with the influence of environmental degradation on the change of the mechanical properties of polymer nanocomposites. The tested material was polyamide (PA) filled with nanoclay fillers Cloisite 30B, Cloisite $93 \mathrm{~A}$ and Cloisite $\mathrm{Na}+$ in a volume of 2,4 and $6 \mathrm{wt} \%$. Test samples were produced by injection molding and were subjected to 540 hours and 1080 hours of UV radiation. The change of mechanical properties of PA6/MMT nanocomposite systems after the ageing in the UV chamber was studied by tensile test and Charpy impact resistance test. Article also compares structure of PA6/MMT nanocomposite.
\end{abstract}

\section{Introduction}

Polymer composites are most common used among all types of composite materials [1]. Nanocomposites are a new class of composites that are particle-filled composites in which at least one dimension of the dispersed particles is in the nanometer range $(<100 \mathrm{~nm})$. In recent years, nanocomposites received a great interest in governmental, industrial and academic studies [2].

Nanomaterials can be classified into nanostructured materials and nanophase/nanoparticle materials [3]. The former usually refer to condensed bulk materials that are made of grains (agglomerates), with grain sizes in the nanometer size range, whereas the latter are usually the dispersive nanoparticles. The nanometer size covers a wide range, from $1 \mathrm{~nm}$ to as large as 100 to $200 \mathrm{~nm}$. To distinguish nanomaterials from bulk, it is crucial to demonstrate the unique properties of nanomaterials and their prospective impacts in science and technology [2, 4].

The development of these new materials will enable the circumvention of classic material performance trade-offs by accessing new properties and exploiting unique synergies between materials, that only occur when the length scale of morphology and the fundamental physics associated with a property coincide, i.e., on the nanoscale level [4,5]. Multifunctional features attributable to polymer nanocomposites consist of improved thermal resistance and/or flame resistance, moisture resistance, decreased permeability, charge dissipation, and chemical resistance [6].

\section{Structure and Properties of Clay}

Nanoclays are clay minerals optimized for use in clay nanocomposites- multi-functional material systems with several property enhancements targeted for a particular application. Polymerclay nanocomposites are an especially well-researched class of such materials. Most commonly used type of layered silicate is montmorillonite (MMT) natural smectic clay 2:1 phyllosilicate [7]. 
Hectorite and saponite are also classified as layered silicates [8]. Owing to high surface area and aspect ratio, MMT clays are of special interest for preparing nanocomposites [9]. The structure of MMT consist of stack of crystalline sheets [10]. Crystal lattice of these sheets comprises twodimensional layers where octahedral layer of aluminium or magnesium is surrounded by two external tetrahedral layers $(2: 1)$ [11]. The thickness of each sheet is considered around 1 nanometer (nm) [7] while the lateral dimension of individual layers may differ from 30 to $2000 \mathrm{~nm}$ depending on the particular silicate [12]. Stack of platelets is held together by electrostatic forces with interlayer distance called d-spacing between the platelets. The interlayer is also characterized by negative sur-face charge where counterions are attracted to the net negative charge within the clay platelets [13]. The exchange of simple inorganic cations is very much depended upon surface charge density which is known as cation ex-change capacity (CEC) expressed by meq/100g [11]. Localization of negative charge is not constant and may vary from layer to layer. Therefore, it is beneficial to consider CEC as an average value of entire crystal [7]. The layered structure of montmorillonite clays is illustrated in Fig. 1.

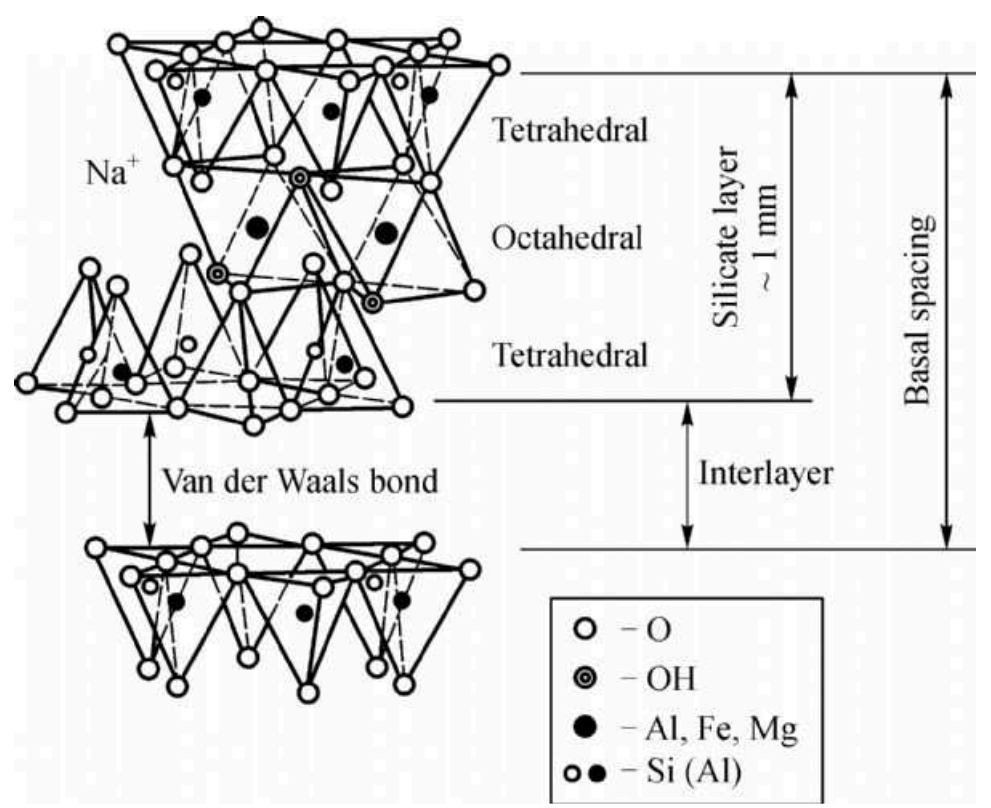

Fig. 1 The layered structure of Montmorillonite

Montmorillonite (MMT) has wide use in polymer nanocomposites for its easy accessibility, a well known intercalation and exfoliation characteristic, high surface area per mass unit and high surface reactivity. MMT layer can have the aspect ratio from $1000 \mathrm{~m}^{2} / \mathrm{g}$ in a highly dispersed systems, and particle surface area of about $750 \mathrm{~m} 2 / \mathrm{g}$. Usually, because of the break of clay layers during the stage of preparation of nanocomposite layers MMT aspect ratio decreases to $300-500 \mathrm{~m}^{2} / \mathrm{g}$. $[4,9,10]$.

\section{Degradation of Polymer Composites}

Polymeric materials properties are changing over the time. Due to time and environmental conditions over the life of polymeric materials occurs therefore unintentional but irreversible changes to their structure and properties. These changes are usually named as ageing, degradation, damage or corrosion. The concept of ageing emphasizes the time factor, which not necessarily means the deterioration of properties. [14,15].

The finished material is exposed over time many internal and external influences. To internal impacts belongs thermodynamic instability, the external factor is especially heat, solar radiation, atmospheric oxygen, ozone, moisture, rain, sulphur and nitrogen oxides, dust fallout, aggressive media (gases, vapours, liquids), ionizing radiation, mechanical force (often variable) and microorganisms. These impacts affect the structure, change it and therefore change the performance characteristics of the polymer. Each of them acts by different mechanisms and affects the different 
polymer structure level. The action of excessively elevated temperatures for a time substantially disrupts the macromolecular polymer chains and results in embrittlement of plastics. At semicrystalline thermoplastics causes additional crystallization which is also manifested by a reduction in ductility and impact the impact strength, sometimes also reducing the stiffness and the mass loss of the polymer $[14,16]$. Testing ageing of polymers is one of the most important tests to the lifetime of product. Ageing tests can be either in real conditions of use of the polymer in a particular application, or using artificial accelerated ageing conditions. Accelerated ageing methods provide test results significantly faster than natural ageing tests $[15,17]$.

\section{Materials and Methods}

The aim of this paper is defining the influence of the nanofiller contents on the mechanical properties of polyamide tested in standard condition according to standards and after ageing in UV chamber. Mechanical properties are strength properties defined in the static tensile test and Charpy impact test. The secondary aim was to check the convenience of usage of MMT nanofiller in PA6 matrix.

Polyamide (PA) is an important group of the thermoplastic excellent solvent resistance and good processibility. Material PA6 Durethan B30S was used as the matrix. Durethan B30S is nonreinforced PA6 used for injection molding with tensile modulus $3200 \mathrm{MPa}$, melt volume-flow rate $100 \mathrm{~cm}^{3} / \mathrm{min}$. Nanocomposite system was formed with PA matrix/nanoclay fillers.

Cloisite nanoclays are the additives into polymers with a high aspect ratio based on montmorillonite made by Southern Clay Products, Inc. The benefits of processing technology results to the high particle surface area $-750 \mathrm{~m}^{2} / \mathrm{g}$ and a high aspect ratio $70-150$. One of the interesting aspects of the use of nanofillers is the low concentration of that filler that needs to be added to the polymer system to obtain desired property improvements.

Cloisite MMT clays used for experiment:

- Cloisite $30 B$ is a natural montmorillonite modified with a quaternary ammonium salt. Specific chemical pre-treatment modifier $\left(\mathrm{MT}_{2} \mathrm{EtOH}\right.$ :methyl, tallow, bis-2-hydroxyethyl, quaternary ammonium) was used for the preparation of Cloisite 30B.

- Cloisite $93 \mathrm{~A}$ is a natural montmorillonite modified with a ternary ammonium salt. Specific chemical pre-treatment modifier $\left(\mathrm{M}_{2} \mathrm{HT}\right.$ : methyl, dehydrogenated tallow ammonium salt) was used to prepare Cloisite 93A.

- Cloisite $\mathrm{Na}^{+}$is a natural montmorillonite. This plastic additive improves various plastic physical properties, such as reinforcement, heat deflection temperature (HDT), coefficient of linear thermal expansion (CLTE), and barrier properties.

Typical properties of Cloisite MMT fillers used for experiments are described in Table 1.

Table 1 Typical properties of Cloisite MMT fillers

\begin{tabular}{|c|c|c|c|}
\hline Properties & $\begin{array}{c}\text { Nanoclay } \\
\text { Cloisite 30B }\end{array}$ & $\begin{array}{c}\text { Nanoclay } \\
\text { Cloisite 93A }\end{array}$ & $\underset{\text { Cloisite } \mathrm{Na}^{+}}{\text {Nanoclay }}$ \\
\hline Moisture (\%) & $<3$ & $<3$ & $4-9$ \\
\hline $\begin{array}{l}\text { Typical Dry Particle Size } \\
\mathrm{d}_{50}(\mu \mathrm{m})\end{array}$ & $<10$ & $<40$ & $<25$ \\
\hline Colour & White & White & Off White \\
\hline Packed Bulk Density (g/l) & 365 & 440 & 568 \\
\hline Density (g/cc) & 1.98 & 1.88 & 2.86 \\
\hline XRay d $\mathrm{d}_{001}(\mathrm{~nm})$ & 1.85 & 2.79 & 1.17 \\
\hline
\end{tabular}

The nanocomposites were obtained in two steps in air atmosphere using co-rotating twinscrew extruder Buhler BTSK 20/40D. Configuration of extruder BTSK 20/40D: screw configuration - $\mathrm{K} 3$, torque $-32 \mathrm{Nn}$, temperature of the melt in the screw head $-208^{\circ} \mathrm{C}$, input power $0,54 \mathrm{~kW}$, screw speed $-250 \mathrm{rpm}$, melt pressure in the screw head $-1 \mathrm{bar}$, temperature zones $-190{ }^{\circ} \mathrm{C}$ $-200{ }^{\circ} \mathrm{C}-200{ }^{\circ} \mathrm{C}-200{ }^{\circ} \mathrm{C}-195{ }^{\circ} \mathrm{C}$, cooling - air. The final material was air cooled and pelletized to a 
length of $3 \mathrm{~mm}$ with diameter $1.5 \mathrm{~mm}$. Each material was blended at the three volume concentrations of $2 \%, 4 \%$ and $6 \%$ of nanofiller. In the research, a single screw injection moulding machine type Ergotech pro 25-80 manufactured by Demag Mannesmann $\mathrm{GmbH}$ was used for produce specimens for tensile test and impact test.

Tension testing in the static tension test of the obtained injection moulds with various amount of nanoclay fillers in the form of standardized specimens used in strength testing was conducted using a standard testing machine TIRA test 2300. Testing of obtained PA/MMT specimens was conducted according to STN-EN ISO 527-1:2012 standard; the accuracy of the test was $1 \mathrm{~N}$, and the speed of tension was $25 \mathrm{~mm} / \mathrm{min}$. Five measurements were taken to determine the arithmetic mean of tensile strength value.

Determining impact resistance of materials using Charpy impact apparatus is conducted according to STN EN ISO 179-1:2011 standard. Determining impact resistance with Charpy impact apparatus is done by measuring the energy to breaking the specimen by measuring the angle of the pendulum with hammer after breaking the specimen. Impact strength was calculated as the ratio of the force needed to dynamically break a specimen to the cross-sectional area of the specimen. Ten measurements were taken to determine the arithmetic mean of Charpy impact.

The tests were performed under standard conditions and to investigate the impact of the ageing, the samples were exposed to UV light in the chamber for $540 \mathrm{hrs}$ and $1080 \mathrm{hrs}$.

The samples were irradiated continuously for 12 hours, followed by a 12 hour rest interval. To determine the changes of mechanical properties after ageing, tensile and impact tests were made.

\section{Results and Discussion}

Tensile strength results for obtained nanocomposites specimens before and after ageing in UV chamber are presented in Fig. 2, Fig.3 and Fig.4.

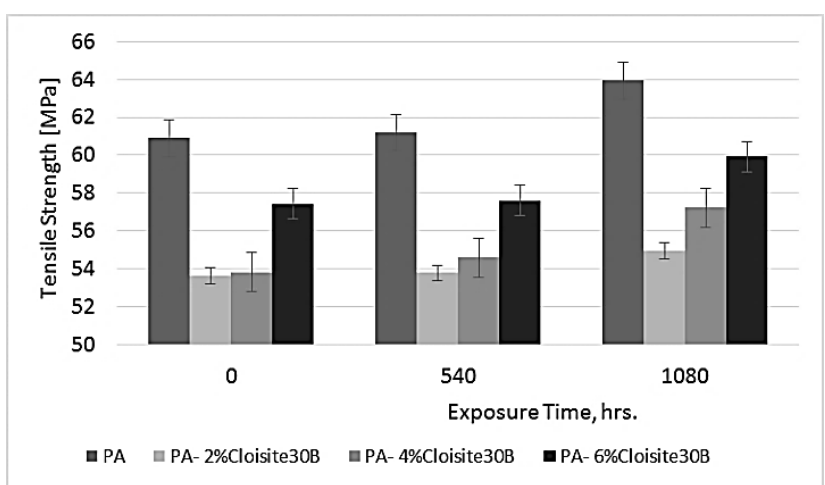

Fig. 2 Tensile strength of PA/ Cloisite30B materials after ageing

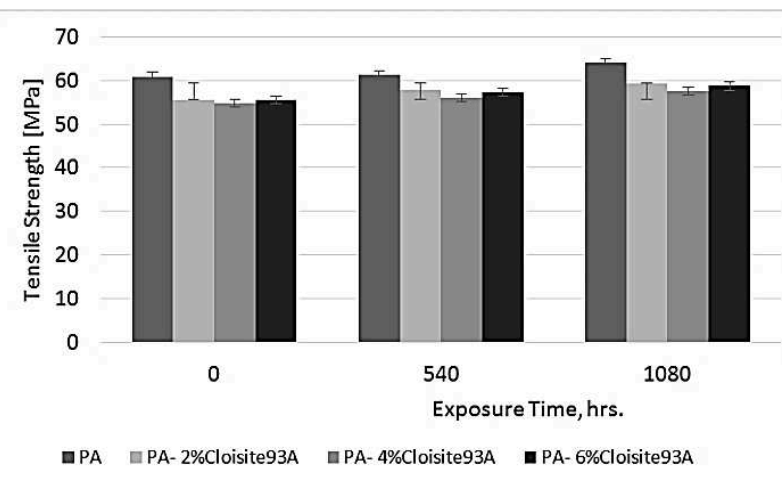

Fig. 3 Tensile strength of PA/ Cloisite93A materials after ageing

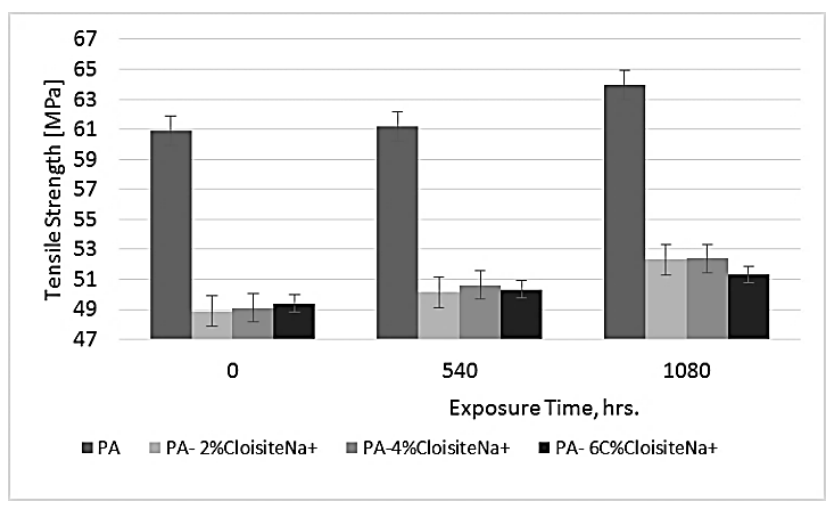

Fig. 4 Tensile strength of PA/ CloisiteNa+ materials after ageing 
The addition of nanofiller to base material caused the decrease of tensile strength of final material. Biggest change was observed at $\mathrm{PA} / 2 \%$ Cloisite $\mathrm{Na}+$, decrease of $19.74 \%$ in comparison to the raw material. Ageing in UV chamber for 1080 hours caused increase of tensile strength by $4.98 \%$ at raw material. This exposure increased also tensile strength of filled materials - by $6.32 \%$ (material PA/ 4\%Cloisite30B), by 6.92\% (material PA/ 2\%Cloisite93A) and by $7.06 \%$ (material $\mathrm{PA} / 2 \%$ CloisiteNa+) in comparison to the test in standard conditions without ageing.

Charpy impact of nanocomposites specimens before and after ageing in UV chamber are presented in Fig. 5, Fig.6 and Fig.7.

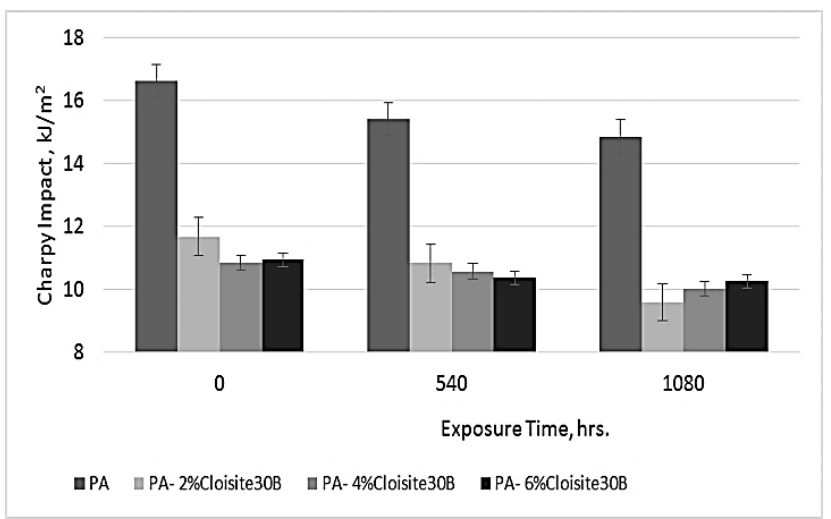

Fig. 5 Charpy impact of PA/ Cloisite30B materials after ageing

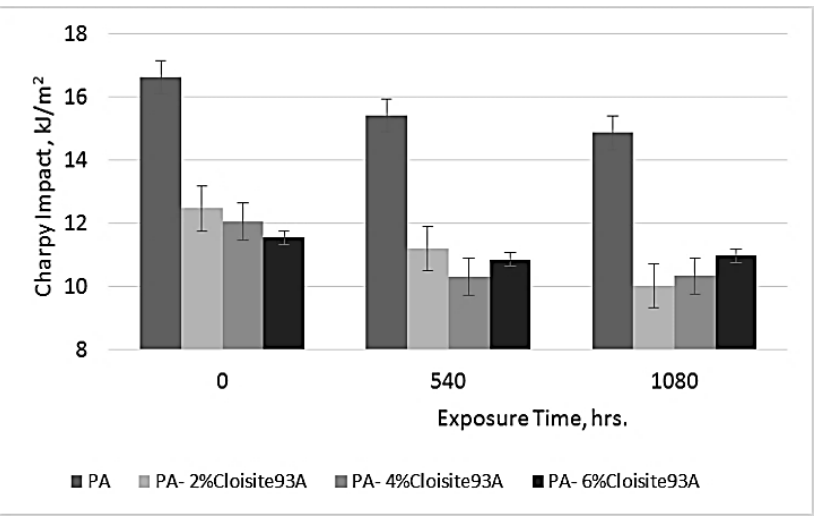

Fig. 6 Charpy impact of PA/ Cloisite93A materials after ageing

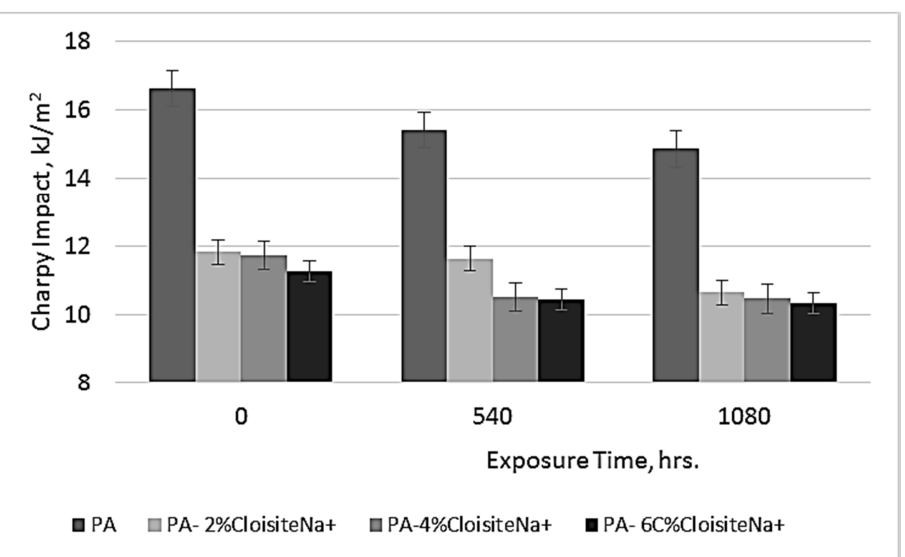

Fig. 7 Charpy impact of $\mathrm{PA} / \mathrm{CloisiteNa}+$ materials after ageing

Addition of filler to base material decrease Charpy impact strength of nanocomposite. Biggest change was observed in material PA/4\% Cloisite 30B - decrease of $34.92 \%$ in comparison to raw material. Exposure of raw material to UV light for 1080 hours decreased impact strength by $10.70 \%$. This exposure also decreased impact strength of filled materials - by $17.82 \%$ (material PA/ $4 \%$ Cloisite30B), by $19.65 \%$ (material PA/ 2\%Cloisite93A) and by $10.83 \%$ (material PA/ $4 \% \mathrm{CloisiteNa}+$ ) in comparison to the test in standard conditions without ageing.

The structure of materials was studied in scanning electron microscopy type Tesla BS 340 . Each material was observed on the fracture surfaces of samples after Charpy impact test. Structures of selected materials are shown on Fig. 8 to Fig. 12. 

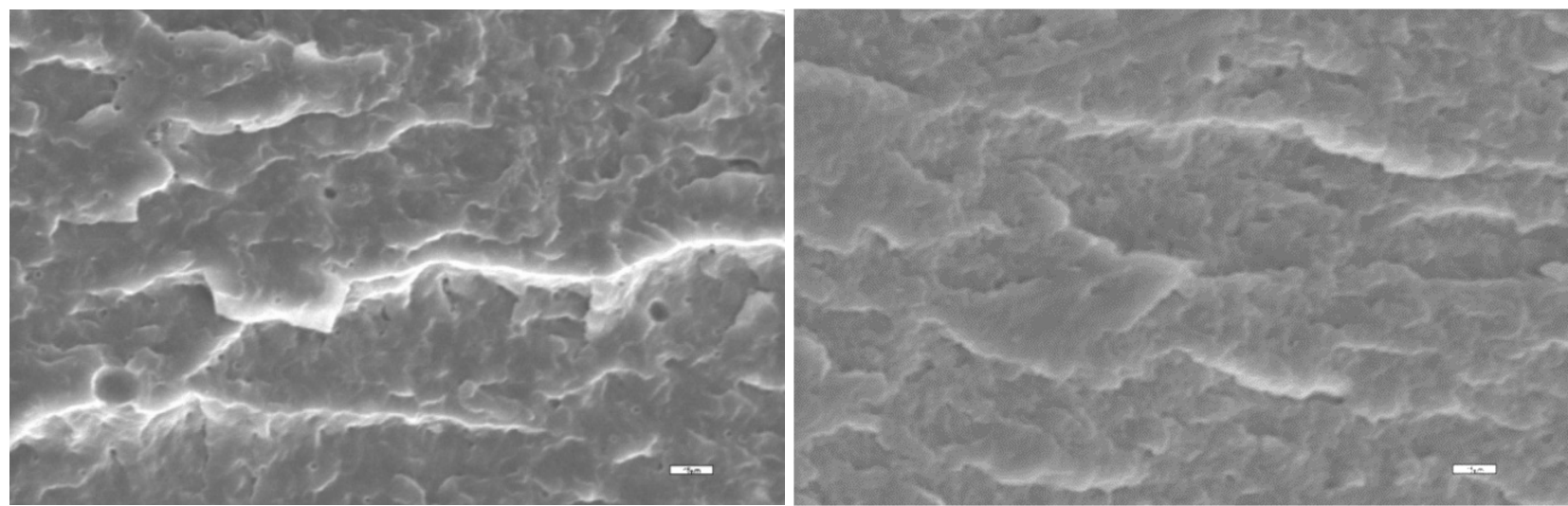

Fig. 8 Structure of material PA6, 2500x

Fig. 9 Structure of material PA6/4\%Cloisite30B
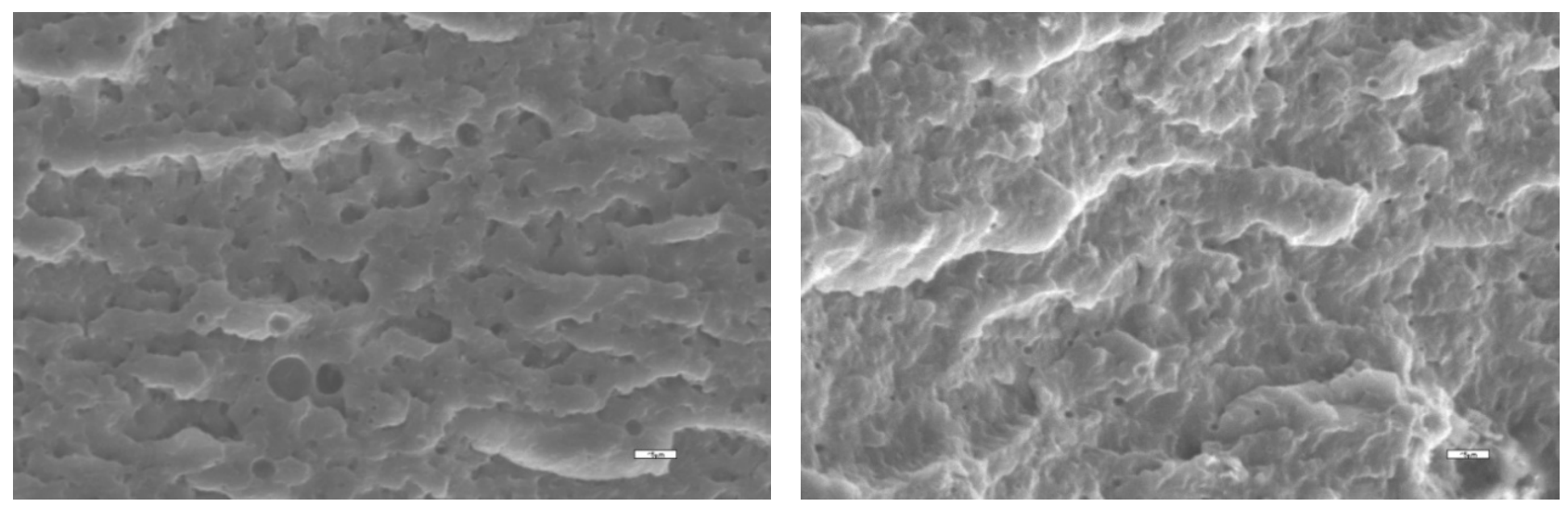

Fig. 10 Structure of material PA6/4\%Cloisite93A Fig. 11 Structure of material PA6/4\%CloisiteNa+

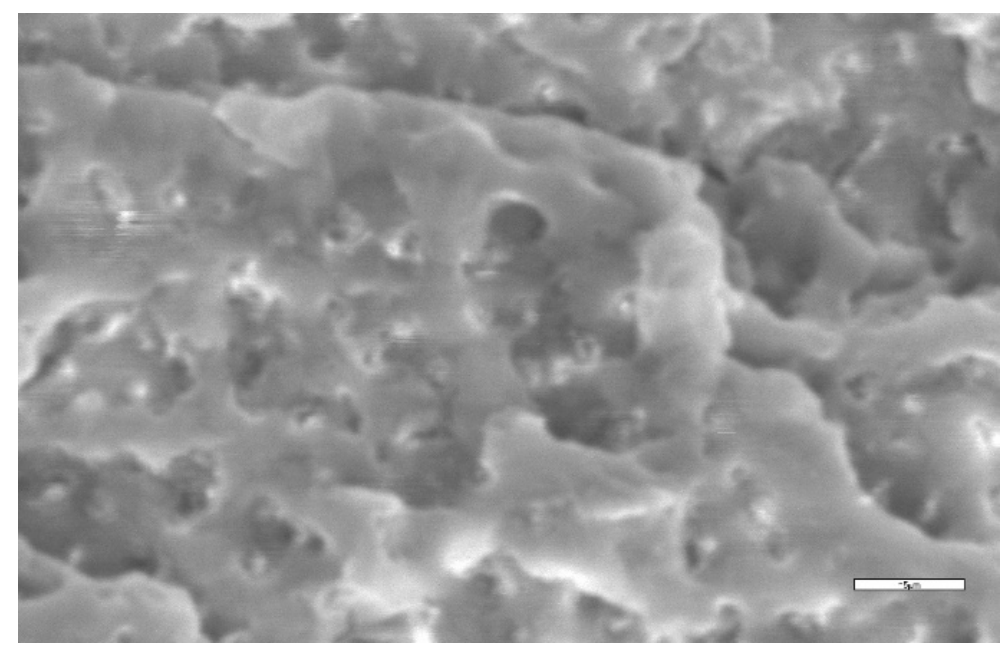

Fig. 12 Structure of material PA6/6\%CloisiteNa+, 5000x

Structure of PA6/4\%Cloisite30B (Fig. 11) is homogeneous, does not show the filler clusters and other contaminants in the material itself. Figure 10 shows the structure of the material PA6 / 4\% Cloisite93. It can be seen that the exfoliation of the filler was substantially complete with no visible clusters of filler. On Fig. 11 it is possible to see air bubbles with diameter 3-7 $\mu \mathrm{m}$ in small amount. Figure 12 shows that exfoliation of Cloisite $\mathrm{Na}+$ in PA matrix was not performed sufficiently with visible not split filler and small amounts of air bubbles.

\section{Summary}

The aim of the contribution was to investigate the impact of nanofiller in selected mechanical properties of prepared nanocomposites. Cloisite 30B, Cloisite 93A and Cloisite $\mathrm{Na}+$ were added to polyamide matrix with content of $2 \%, 4 \%$ and $6 \%$ of filler. Tensile strength and Charpy impact 
strength were evaluated in new state and after ageing. Ageing of nanocomposites was performed by exposure of samples to UV radiation for 540 and 1080 hours in the chamber. Based on this study, we can conclude that each material was affected by various affect. This phenomenon can be explained by the volume particle size distribution of the cross section of the material that prevents the complete penetration of the UV radiation. Investigated nanocomposites showed increased strength with an increasing amount of fillers. The reason was sufficient split of the filler particles and exfoliation or intercalation into polyamide. UV radiation caused the dissolution of macromolecular polymer chain and this resulted in their embrittlement. This resulted in additional crystallization and resulted in a reduction of toughness for each test material.

That contribution also pointed out that the replacement of the currently used materials for injection molding with polymer nanocomposites in granular form does not entail any restrictions or injection process necessary adjustments.

\section{Acknowledgement}

This project has received funding from the European Union's Horizon 2020 research and innovation programme under the Marie Skłodowska-Curie grant agreement No 734205”.

\section{References}

[1] J. Dobránsky, F. Botko, E. Vojnova, Heat transfer monitoring of injection mold, MM Science Journal, October (2016) 1073-1076.

[2] J. Habr, J. Bobek et al. Adhesion additive influence on polyamide nano polymer composite properties, Defect and Diffusion Forum 368 (2016) 142-145.

[3] B. Duleba, E. Spišák et al. Prediction and Verification of Compatibility of MMT Nanofiller in PA6 Matrix, Key Engineering Materials 635 (2015) 194-197.

[4] Q. T. Nguyen, D. G. Baird, Preparation of polymer-clay nanocomposites and their properties, Advances in Polymer Technology 25 (2006) 270-285.

[5] J. Dobránsky, L. Běhálek, P. Baron, Gate location and its impact to flowing characteristics of plastic moldings, Key Engineering Materials 669 (2016) 36-43.

[6] O. V. Suberlyak, V. V. Krasinskyi et al. Influence of Aluminosilicate Filler on the Physicomechanical Properties of Polypropylene-Polycaproamide Composites, Materials Science 50/2 (2014) 296-302.

[7] B. Lepoittevin, N. Pantoustier, et al. Polymer/layered silicate nanocomposites by combined intercalative polymerization and melt intercalation: a master batchprocess, Polymer 44/7 (2003) 2033-2040.

[8] S.J. Ahmadi, Y.D. Huang, W. Li, Synthetic routes, properties and future applications of polymer-layered silicate nanocomposites, Journal of Materials Science 39 (2004) 1919-1925.

[9] J.M. Herrera-Alonso, Z. Sedlakova, E. Marand, Gas barrier proper-ties of nanocomposites based on in situ polymerized poly (n-butyl methacrylate) in the presence of surface modified montmorillonite, Journal of Membrane Science 349 (2010) 251-257.

[10] S. Nazarenko, P. Meneghetti, et al. Gas barrier of polystyrene montmorillonite clay nanocomposites: Effect of mineral layer aggregation, Journal of Polymer Science Part B: Polymer Physics 45 (2007) 1733-1753.

[11]N.N. Bhiwankar, R.A. Weiss, Melt intercalation/exfoliation of polystyrene-sodiummontmorillonite nanocomposites using sulfonated polystyrene ionomer compatibilizers, Polymer 47 (2006) 6684-6691. 
[12]R.K. Bharadwaj, Modelling the barrier properties of polymer-layered silicate nanocomposites, Macromolecules 34 (2001) 9189-9192.

[13] S. Su, Ch. A. Wilkie, Exfoliated poly (methyl methacrylate) and polystyrene nanocomposites occur when the clay cation contains a vinyl monomer, Journal of Polymer Science Part A: Polymer Chemistry 41/8 (2003) 1124-1135.

[14] T. Jachowicz, T. Garbacz et al. Investigation of selected properties of injection-molded parts subjected to natural aging, International Journal of polymer and characterization 20/4 (2015) 307315.

[15]Krzyzak, M. Łagožna et al. Selected Properties of Composites with Polypropylene after Ageing, Key Engineering Materials 635 (2015) 212-215.

[16] L.K. Massey, The effects of UV light and weather on plastics and elastomers, William Andrew Publishing, 2nd ed. (2007) 489 p.

[17] A.C. Tavares, J.V. Gulmine, C.M. Lepienski, L. Akcelrud, The effect of accelerated ageing on the surface mechanical properties of polyethylene, Polymer Degradation and Stability 81 (2003), 367-373. 